\title{
Use of UHPC in Bridge Structures: Material Modeling and Design
}

\author{
Oguz Gunes, ${ }^{1}$ Seda Yesilmen, ${ }^{2}$ Burcu Gunes, ${ }^{2}$ and Franz-Joseph Ulm ${ }^{3}$ \\ ${ }^{1}$ Civil Engineering Department, Cankaya University, 06810 Ankara, Turkey \\ ${ }^{2}$ Civil Engineering Department, Atilim University, 06836 Ankara, Turkey \\ ${ }^{3}$ Civil and Environmental Engineering Department, Massachusetts Institute of Technology, Cambridge, MA 02139, USA
}

Correspondence should be addressed to Oguz Gunes, ogunes@alum.mit.edu

Received 19 December 2011; Accepted 11 February 2012

Academic Editor: Gai-Fei Peng

Copyright () 2012 Oguz Gunes et al. This is an open access article distributed under the Creative Commons Attribution License, which permits unrestricted use, distribution, and reproduction in any medium, provided the original work is properly cited.

\begin{abstract}
Ultra-high-performance concrete (UHPC) is a promising new class of concrete material that is likely to make a significant contribution to addressing the challenges associated with the load capacity, durability, sustainability, economy, and environmental impact of concrete bridge infrastructures. This paper focuses on the material modeling of UHPC and design of bridge girders made of UHPC. A two-phase model used for modeling the behavior of UHPC was briefly discussed, and the model was implemented in a preliminary design case study. Based on the implemented design and the reported use of UHPC in bridge applications, the advantages, limitations, and future prospects of UHPC bridges were discussed, highlighting the need for innovative research and design to make optimum use of the favorable properties of the material in bridge structures.
\end{abstract}

\section{Introduction}

Bridge structures are the critical links in the transportation networks, and their condition is important for transportation safety and economy. Vehicle miles of travel on the US highways is steadily increasing (Figure 1(a)), and despite the progress made in the last two decades, nearly $25 \%$ of the 603,000 bridges in the US are either structurally deficient or functionally obsolete (Figure 1(b)) [1, 2]. The estimated 5 -year investment needed to bring bridges and roads to acceptable levels is $\$ 930$ billion and the projected shortfall from this investment is $\$ 550$ billion [3]. Therefore, there is an urgent need for better materials and methods to better look after our existing bridges while building new ones to last longer.

Considering that concrete is the most commonly used material for highway bridges - $64 \%$ of all US highway bridges and $33 \%$ of the structurally deficient bridges are made of concrete [1] -improved concrete solutions can make a big impact on addressing the challenges of bridge infrastructure. A promising such solution is the ultra-high-performance concrete (UHPC). UHPC is a new generation of fiber reinforced cementitious material composed of Portland cement, silica fume, mineral fillers, fine silica sand, superplasticizer, water, and steel fibers. A typical UHPC material has a design compressive strength of $f_{c}^{\prime}=200 \mathrm{MPa}(29 \mathrm{ksi})$ and a ductile tensile strength of $f_{t}^{\prime}=10-15 \mathrm{MPa}(1.5 \mathrm{ksi}-2.2 \mathrm{ksi})$, which are achieved by optimizing both the packing density of the matrix and the length-diameter spectrum of the steel fiber reinforcement [4-6]. Because of the material's ability to dissipate energy through superior bonding between the matrix and the fiber, UHPC structures are capable of deforming and supporting flexural and tensile loads even after initial cracking. Figure 2 displays the compressive and flexural strength of UHPC in comparison to that of normal concrete [7]. This capacity allows the use of UHPC in bridge girders without passive reinforcement or shear stirrups, saving labor and cost. The high strength of UHPC can also allow smaller section sizes, reducing construction time and labor. UHPC girders are capable of spanning longer distances and mitigating disturbance to ecosystems and natural habitats. Finally, the low permeability and porosity of UHPC leads to high durability and a superior resistance to corrosive attack. Therefore, UHPC material may be a viable solution to current problems in bridge systems.

\section{UHPC Bridge Applications}

Since the development of UHPC, several applications have been realized. These include the world's first UHPC bridge 


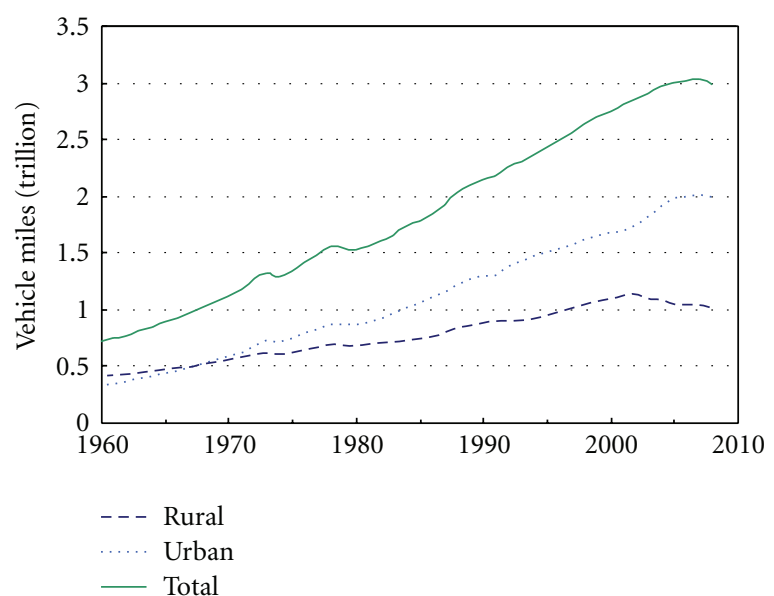

(a)

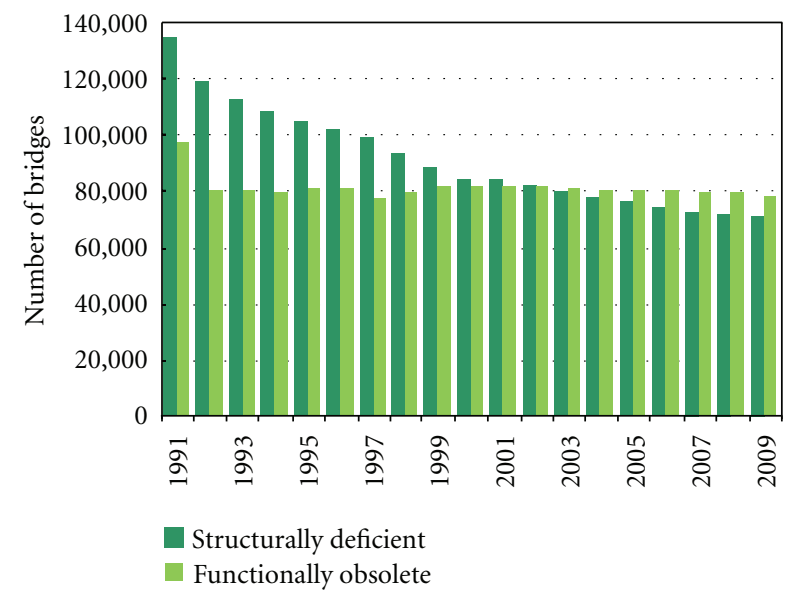

(b)

FIGURE 1: Variation of vehicle miles of travel on US highways (a) and (b) number of structurally deficient and functionally obsolete bridges in the US $[1,2]$.

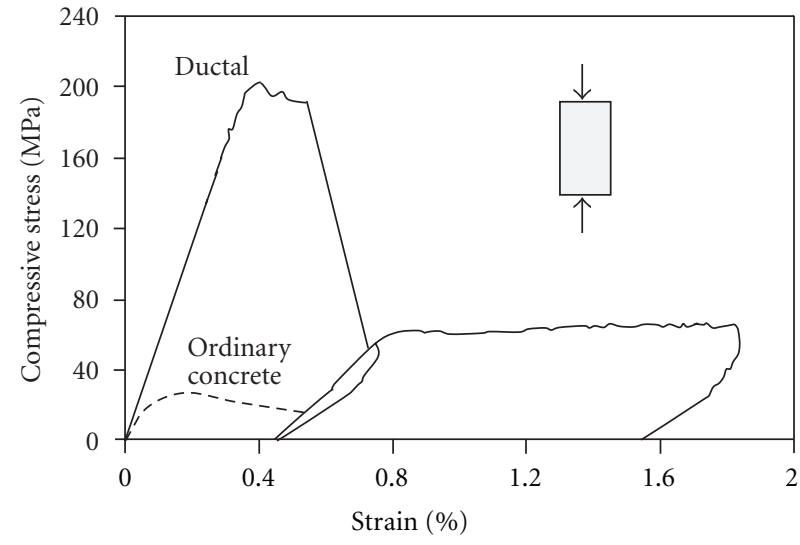

(a)

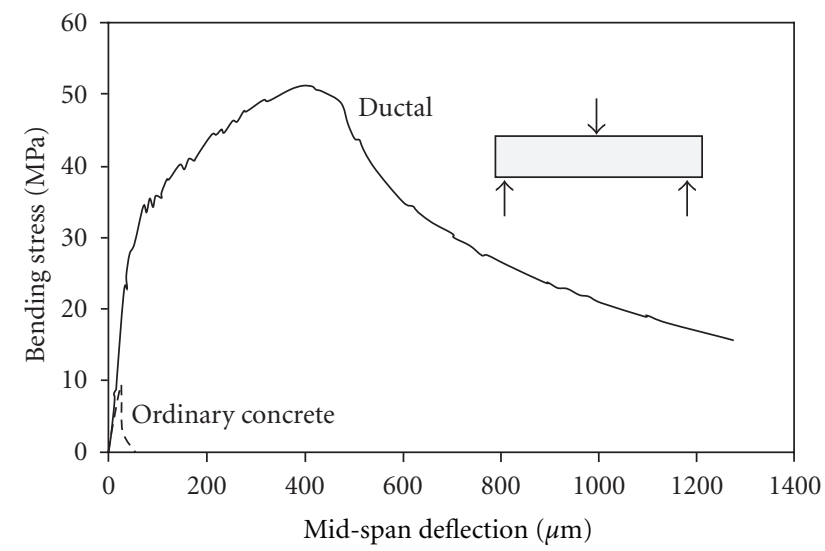

(b)

FIgURE 2: Behavior of Ductal in compression (a) and in bending (b) [7].

on the Bourg lès Valence bypass in Drôme, France (2002) [8], a pedestrian bridge in Seoul, Korea that spans $120 \mathrm{~m}(394 \mathrm{ft})$ with a deck only $3 \mathrm{~cm}$ (1.2 in) thick (2002) [9], and a pedestrian/bike bridge in Sherbrooke, Canada (1997) [10]. In the United States, the Federal Highway Administration (FHWA) has initiated research into innovative bridge systems in which UHPC plays a prominent role. For example, two large-scale structural UHPC beam girder tests were performed at the FHWA Turner-Fairbank Highway Research Center in McLean, Virginia (2001-2002) [4, 11]. Without passive reinforcement and shear stirrups, the prestressed beams displayed superior flexural and shear resistance over normal strength prestressed concrete, which underscored the great potential of this new material for large-scale structural applications.

UHPC was also used in several bridge projects in the US [11-16]. The first application was at the Mars Hill Bridge in Wapello County, Iowa, completed in 2006. In this $108 \mathrm{ft}$ span bridge, three 42 in deep UHPC girders, modified from the standard Iowa bulb-tee design, were used (Figure 3(a)). No traditional shear reinforcement was used in the girders. A similar application was completed in 2008 at the Cat Point Creek Bridge near Warsaw, Virginia. Five 45 in deep prestressed concrete bulb-tee beams were used in one of the ten $81.5 \mathrm{ft}$ spans of this bridge (Figure 3(b)). Realizing the need for new structural shapes optimized for UHPC in bridges, the pi girders developed in an FHWA-initiated research program were used in Jakway Park Bridge near Aurora in Iowa. Three abutted adjacent pi girders were used in the main span of this bridge (Figure 3(c)). Other bridge applications of UHPC in the US included bridge decks made of UHPC and use of UHPC to fill the deck-level connections between girders.

\section{Research Significance}

The recent development of UHPC is based on advances in the materials science of cementitious materials, producing materials with improved mechanical and durability properties. 


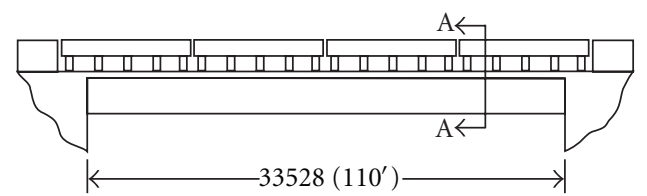

A-A
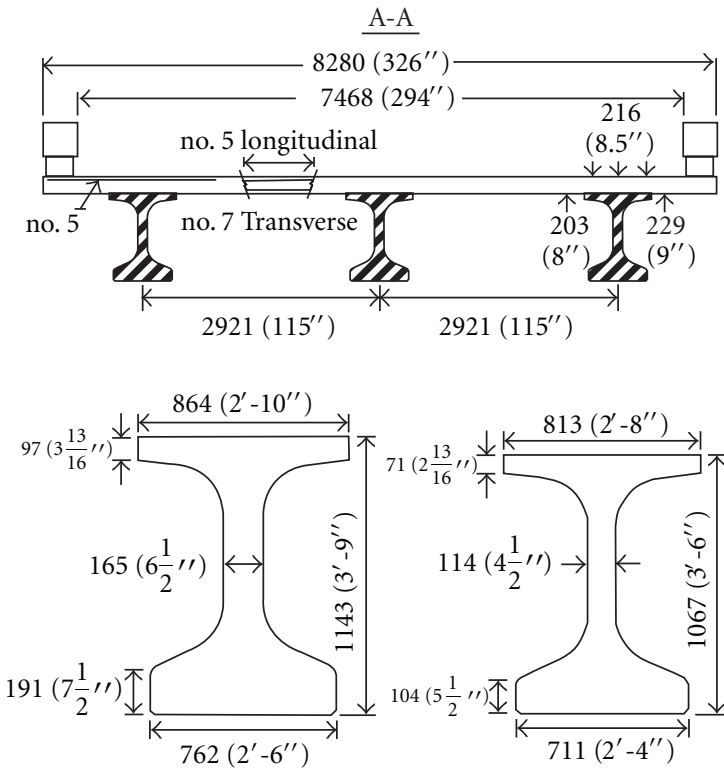

Standard PCBT-45

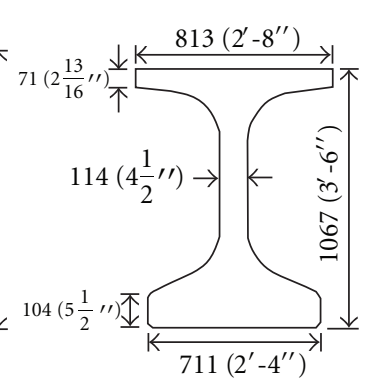

Modified PCBT-45

(a) Mars Hill Bridge, Iowa (2006)
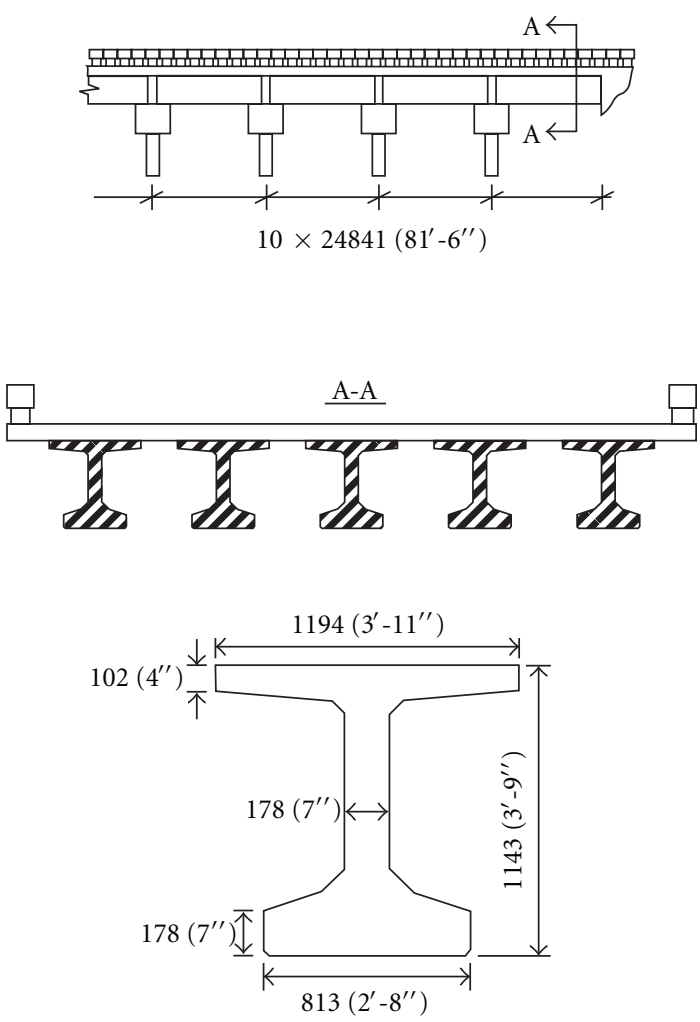

45 in bulb-T beam

(b) Cat Point Creek Bridge, Virginia (2008)

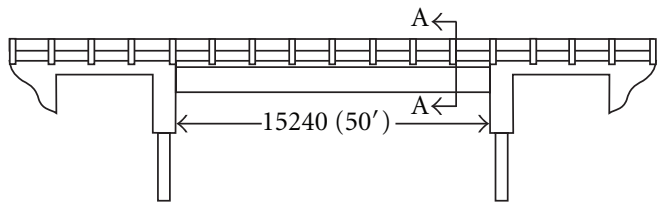

$\underline{\mathrm{A}-\mathrm{A}}$
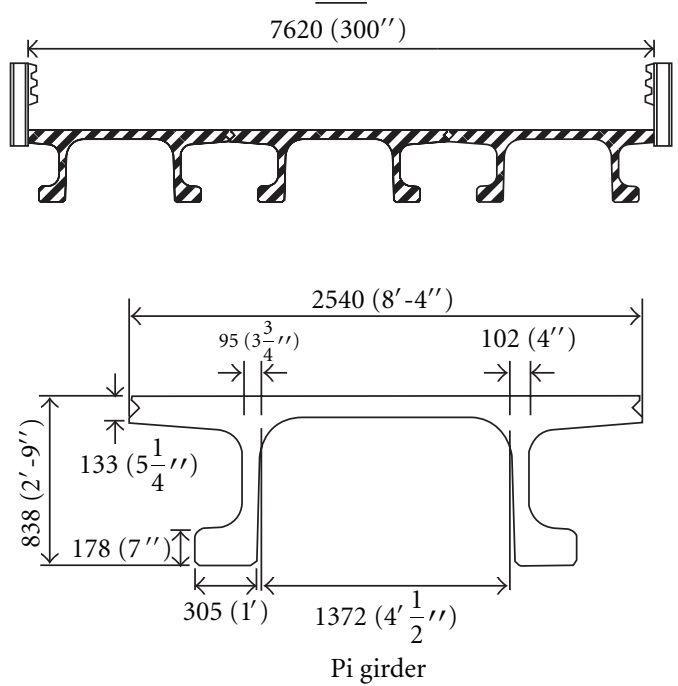

(c) Jakway Park Bridge, Iowa (2008)

FIGURE 3: Early UHPC bridge applications in the US (in mm (ft-in)). 
TABLE 1: Input parameters of the 1D UHPC model and typical values for Ductal derived from a notched tensile plate test [4].

\begin{tabular}{llcc}
\hline & Description & For UHPC & SI \\
\hline$C_{M}$ & Composite matrix stiffness & $53.9 \mathrm{GPa}$ & $(7820 \mathrm{ksi})$ \\
$C_{F}$ & Composite fiber stiffness & $0 \mathrm{GPa}$ & $(0 \mathrm{ksi})$ \\
$M$ & Composite interface stiffness & $1.65 \mathrm{GPa}$ & $(240 \mathrm{ksi})$ \\
$f_{t}$ & Brittle tensile strength of composite matrix & $0.7 \mathrm{MPa}$ & $(0.1 \mathrm{ksi})$ \\
$k_{M}$ & Postcracking tensile strength of composite matrix & $6.9 \mathrm{MPa}$ & $(1 \mathrm{ksi})$ \\
$f_{y}$ & Tensile strength of composite fiber & $4.6 \mathrm{MPa}$ & $(0.67 \mathrm{ksi})$ \\
\hline
\end{tabular}

Considerable effort is required to transfer and implement the knowledge gained at the material level in structural engineering and design. Reaching this goal requires research into the link between the in situ behavior of the materials and the resulting structural performance. Aside from empirical approaches, based on large-scale testing of structures, recent progress in constitutive modeling of materials and modelbased simulation can considerably contribute to attaining this goal. In fact, an appropriate material model for UHPC allows simulation of the behavior of the material. Furthermore, the implementation of this model in design allows for optimization of a material for a given structure [17], or vice versa, optimization of a structure or structural element for a given material. A robust model developed at MIT was briefly discussed and was implemented in a realistic preliminary design case study. The optimization of a design solution first requires the adoption of appropriate design criteria for UHPC structures subjected to a specific loading. In contrast to standard reinforced concrete design criteria, based primarily on maximum material strength criteria, UHPC must be based on a critical crack opening below which the material achieves capacity with high confidence. In this paper, we adapt the maximum crack opening provision issued by the French Association of Civil Engineering (AFGC) [18]. The results of this design implementation provided valuable information about efficient use of UHPC in bridges and the areas where further research and development is needed.

\section{UHPC Material Model}

UHPC material achieves a high tensile strength as well as a ductile tensile behavior through an optimized combination of high-strength concrete and high-strength fibers, which allows stress transfer from the matrix to the fibers after initial crack formation. Hence, a proper mechanical model must take into account the characteristic behavior and contributions of each constituent material as well as their interaction before and after cracking takes place. Figure 4(a) shows a rheological model proposed by Chuang and Ulm [19] to describe the tensile behavior of UHPC. This is a twophase model representing the individual contributions of the matrix and the fibers as well as their interaction particularly in the postcracking region which includes permanent deformation and damage. The main advantage of such a rheological model is that it allows model-based optimization of UHPC structures. The 1D model provided in the figure is sufficient for the purposes of discussions in this paper, the reader is referred to [4] for the $3 \mathrm{D}$ model formulation.

The rheological model shown in Figure 4(a) is composed of two parallel components which represent the macroscopic behaviors of the constituent materials, that is, the matrix and the fibers. An elastic spring (stiffness $C_{M}$ ) and a brittle-plastic crack device (crack strength $f_{t}$; frictional strength $k_{M}$ ) model the elastic brittle-plastic behavior of the composite matrix. The composite fiber behavior is governed by an elastoplastic material law, described by an elastic spring (stiffness $C_{F}$ ) in series with a friction element (strength $f_{y}$ ). Additionally, the two parallel elements are coupled by an elastic spring of stiffness $M$, which links the irreversible matrix behavior ( strain $\varepsilon_{M}^{p}$ ) with the irreversible fiber reinforcement behavior (strain $\left.\varepsilon_{F}^{p}\right)$. These 6 model parameters $\left(C_{M}, C_{F}, M, f_{t}, k_{M}\right.$, and $f_{y}$ ) govern the composite material behavior, and they can be calculated from the macroscopic stress-strain response of the composite material [19].

For a UHPC material, the compressive strength values are readily available from the manufacturer. Furthermore, the six model parameters that characterize the tensile behavior of UHPC, $\left(C_{M}, C_{F}, M, f_{t}, k_{M}\right.$, and $\left.f_{y}\right)$, should be derived from a tensile-notched plate test, which is generally provided by the UHPC manufacturer with high accuracy (and small standard deviation). The rationale behind using notched tensile data is that the notched configuration best reflectsin an average sense-UHPC structural behavior, particularly after cracking. Figure 4(b) displays the results of a notched plate test for Ductal provided by Lafarge, from which we extract the values of the model parameters in Table 1.

\section{Preliminary Design Implementation: UHPC Bulb-T Bridge Girders}

In order to better understand the impact of using UHPC in design of ordinary highway bridges, step-by-step preliminary load and resistance factor design (LRFD) calculations are provided in this section for a sample bridge provided by the Virginia DOT, which is a $108 \mathrm{ft}(32.92 \mathrm{~m})$ span bridge to be constructed using 8 PCBT-45 VDOT Bulb-T sections made of UHPC, overlaid by a lightweight concrete slab. The material model presented in the previous section was used to determine the section capacities and the design results as well as some optimization possibilities were discussed. 


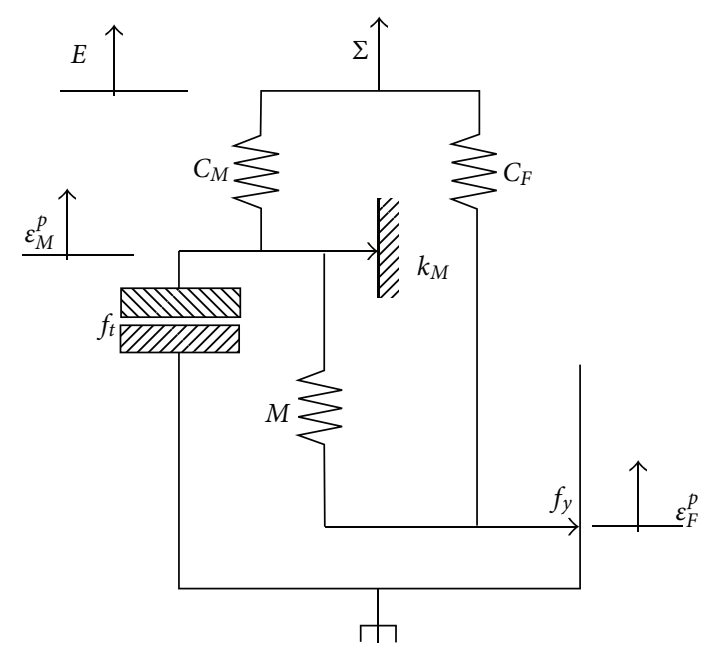

(a)

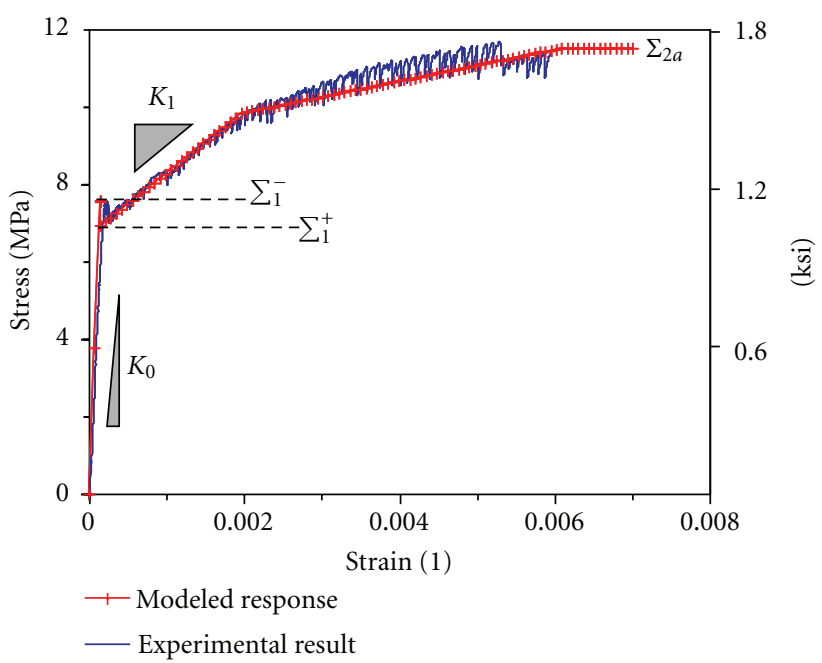

(b)

FIgURE 4: The two-phase rheological model of UHPC (a) and the comparison of model prediction with experimental data (b).

5.1. Design Principle. The design was based on LRFD method adopted for ultra-high-performance concrete structure (UHPC) design. The aim of the design is

$$
\forall J=\text { SLS, ULS, } \quad \sum_{i=1}^{N}\left(\alpha_{i} \psi_{i} \gamma_{i} Q_{i}\right)^{J} \leq(\phi R)^{J},
$$

where the left-hand side represents the factored design load, to be determined according to the current standards based on LRFD specifications, with:

$Q_{i}$ : nominal loads (dead loads and live loads);

$\alpha_{i}$ : load factors;

$\psi_{i}$ : load combination factors;

$\gamma_{i}$ : importance factors.

The right-hand side represents the characteristic resistance of the UHPC section:

$R$ : mean load capacity of the UHPC structural element, which is achieved at a specific maximum allowable crack opening for the UHPC material;

$\phi$ : design strength reduction factor.

For prestressed concrete components, the load cases considered are presented below.

The Service Limit State $(J=S L S)$. The factored load of the service limit state corresponds to the LRFD service III state for tensile stresses in prestressed concrete components, for which:

$$
\sum_{i=1}^{N}\left(\alpha_{i} \psi_{i} \gamma_{i} Q_{i}\right)^{\mathrm{SLS}}=1.0(\mathrm{DC}+\mathrm{DW})+0.8(\delta \times \mathrm{LL}+\mathrm{IM})
$$

where DC: dead load of structural components and nonstructural attachments; DW: future wearing surface on slab; $\delta \times$ LL: design truck or design tandem with dynamic allowance $(\delta=1.33)$. The design truck is the HS20 design truck specified in the standard AASHTO specifications [20]. The design tandem consists of a pair of $25 \mathrm{kip}(111.2 \mathrm{kN})$ axles spaced at $4 \mathrm{ft}(1.22 \mathrm{~m})$ apart; IM: design lane load of $0.64 \mathrm{kip} /$ $\mathrm{ft}(9.34 \mathrm{kN} / \mathrm{m})$ without dynamic allowance.

The characteristic resistance in the service limit state is to be determined for an uncracked UHPC section:

$$
(\phi R)^{\mathrm{SLS}}=\phi R(\llbracket w \rrbracket=0) .
$$

The Ultimate Limit State $(J=U L S)$. The factored load of the ultimate limit state corresponds to the LRFD strength I for ultimate strength calculation, for which:

$$
\sum_{i=1}^{N}\left(\alpha_{i} \psi_{i} \gamma_{i} Q_{i}\right)^{\mathrm{ULS}}=1.25 \mathrm{DC}+1.50 \mathrm{DW}+1.75(\delta \times \mathrm{LL}+\mathrm{IM}) .
$$

The characteristic resistance in the ultimate limit state is to be determined for a maximum allowable crack opening $\llbracket w \rrbracket^{\text {lim }}$ of the UHPC material:

$$
(\phi R)^{\mathrm{SLS}}=\phi R\left(\llbracket w \rrbracket \leq \llbracket w \rrbracket^{\lim }=0\right) .
$$

For an unreinforced structural component (e.g., unreinforced UHPC web in shear design), the maximum allowable crack opening for the UHPC is taken as [18]:

$$
\llbracket w \rrbracket_{\text {un }}^{\lim }=0.01 \text { in }=0.254 \mathrm{~mm} .
$$


For a reinforced (including prestressed) structural component (e.g., prestressed UHPC bottom flange in bending design), the maximum allowable crack opening is

$$
\llbracket w \rrbracket_{\mathrm{re}}^{\lim }=\min \left(\frac{L_{f}}{4}, \frac{h}{100}\right),
$$

where $L_{f}$ : length of fibers in UHPC material and $h$ : the UHPC section height (excluding a non-UHPC composite deck).

The restriction of the crack opening to maximum values ensures (1) a ductile failure behavior in the ultimate limit state; (2) avoidance of excessive deflections and bond failure between prestressing strands and UHPC.

5.2. Design Considerations. The presented design is for a composite section composed of a prestressed UHPC section and a lightweight concrete slab, with a span length of $L=$ $108 \mathrm{ft}(32.92 \mathrm{~m})$. The design considerations and constraints specified by the VDOT are listed below.

The beam section considered was the PCBT-45 VDOT Bulb-T section, made of UHPC with a depth of $h=45$ in (1.143 m):

(i) strands are harped unless straight strands without debonding will work;

(ii) strand size: 0.5 in $(12.7 \mathrm{~mm})$ diameter. Diameter of 0.6 in $(15.24 \mathrm{~mm})$ may be considered if needed;

(iii) debonding of strands at beam ends is not permitted;

(iv) average spacing of the 8 beams in the bridge crosssection is $10.083 \mathrm{ft}(3.07 \mathrm{~m})$;

(v) standard web thickness is 7 in $(17.8 \mathrm{~cm})$ for VDOT Bulb-Ts; however, 6 in $(15.24 \mathrm{~cm})$ web will be considered if design is satisfactory;

(vi) interior diaphragms are galvanized steel, while end diaphragms are cast-in-place. Assume $10 \mathrm{lbs} / \mathrm{ft}$ $(0.146 \mathrm{kN} / \mathrm{m})$ including weight of connectors;

(vii) beams are designed as simple spans. Continuity may be in the slabs only or with continuity diaphragms.

The considered slab had the following characteristics:

(i) depth: 8.5 in $(21.6 \mathrm{~cm})$ (includes 0.5 in $(1.27 \mathrm{~cm}$ ) wearing surface (ws) which is not used in computing section properties);

(ii) concrete strength: 4000 psi (28 MPa) and density: $w=$ $125 \mathrm{pcf}$ ( 2 ton $/ \mathrm{m}^{3}$ ) (lightweight concrete);

(iii) slab is composite with beam with hairpin bars spaced 12 in $(30.5 \mathrm{~cm})$ on center on top of beam;

(iv) for construction tolerances of slab, use $20 \mathrm{psf}$ (958 Pa);

(v) for future wearing surface, use $15 \mathrm{psf}(718 \mathrm{~Pa})$;

(vi) for composite dead load, consider weight of rail = $346 \mathrm{lbs} / \mathrm{ft}(5.05 \mathrm{kN} / \mathrm{m})$ (distributed over exterior beam and two interior beams).
TABLE 2: Summary of uniform dead loads per beam.

\begin{tabular}{lcc}
\hline & DC & DW \\
& $\mathrm{lbs} / \mathrm{ft}(\mathrm{kN} / \mathrm{m})$ & $\mathrm{lbs} / \mathrm{ft}(\mathrm{kN} / \mathrm{m})$ \\
\hline UHPC PCBT-45 Beam & $830(12.11)$ & $53(0.77)$ \\
Slab & $840(12.26)$ & \\
Bolster & $61(0.89)$ & \\
$\begin{array}{l}\text { Diaphragms and } \\
\text { Connectors }\end{array}$ & $10(0.15)$ & $115(1.68)$ \\
$\begin{array}{l}\text { Construction tolerance } \\
\text { Rail }\end{array}$ & $20(0.29)$ & $59(0.86)$ \\
Future wearing surface & & $227(3.31)$ \\
\hline Total & $1,761(25.7)$ & \multicolumn{2}{c}{$1,988(29)$} \\
\hline DL $=$ DC + DW & \multicolumn{2}{c}{} \\
\hline
\end{tabular}

5.3. Calculation of Design Loads and Internal Forces. Detailed calculations of the design loads and the internal forces are not provided here for brevity. Rather, summary of the uniform dead loads per beam is provided in Table 2, and the resulting design moment and shear values including the live load effects calculated according to the AASHTO LRFD specifications are provided below.

For service limit state (SLS):

$$
\begin{gathered}
M_{\mathrm{SLS}}\left(x_{M}\right)=4,908 \text { kips- } \mathrm{ft}=6,654 \mathrm{kN}-\mathrm{m}, \\
V_{\mathrm{SLS}}\left(x_{V}\right)=195 \mathrm{kips}=867 \mathrm{kN} .
\end{gathered}
$$

For ultimate limit state (ULS):

$$
\begin{gathered}
M_{\mathrm{SLS}}\left(x_{M}\right)=8,107 \text { kips-ft }=10,992 \mathrm{kN}-\mathrm{m}, \\
V_{\mathrm{SLS}}\left(x_{V}\right)=333 \mathrm{kips}=1,481 \mathrm{kN} .
\end{gathered}
$$

\section{Section Capacities}

This part deals with the determination of the moment and shear capacity of the UHPC PCBT-45 beam section, that is, the right-hand side of the design inequalities (2) and (4). It is based on section equilibrium for a given maximum allowable crack opening, defined by relations (3), (5)-(7).

\subsection{Moment Capacity of Section}

6.1.1. Determination of Mean Moment Capacity. Section moment capacity calculation is based on the following principles:

(1) section equilibrium requires

$$
\begin{aligned}
N_{R} & =\int_{A} \sigma(y) d a=0, \\
M_{R} & =\int_{A} y \sigma(y) d a=0,
\end{aligned}
$$

where $\sigma(y)$ is the longitudinal stress in the crosssection $A$, which varies as a function of $y . N_{R}$ is the normal force, which is zero in this case. The prestress 
in the prestressing strands is taken into account in the integral of the stresses over the cross-section by considering an elastoplastic relation for the prestressing strands:

$$
\sigma\left(y_{p}\right)=\gamma f_{y}^{p}+E_{T} \mathcal{\varepsilon}\left(y_{p}\right) \leq f_{y}^{p}
$$

where $y$ is the prestress level of the tendons (after prestress losses due to creep), $f_{y}^{p}=270 \mathrm{ksi}(1,862 \mathrm{MPa})$ is the yield stress of the prestressing steel, $E_{T}=$ $29,000 \mathrm{ksi}(200 \mathrm{GPa})$ is the elastic stiffness of the prestressing tendons, and $\varepsilon\left(y_{p}\right)$ is the strain in the prestressing strands situated in the cross-section at position $y=y_{p}$

(2) plane section assumption (Navier-Bernoulli): the initially plane section is assumed to remain plane during deformation and normal to the middle axis situated in the center of gravity of the composite cross-section. The strain in any point of the section is therefore given by

$$
\varepsilon(y)=\varepsilon\left(y_{0}\right)-\kappa\left(y-y_{0}\right),
$$

where $\varepsilon\left(y_{0}\right)$ is the strain in the reference axis $y=y_{0}$, and $\kappa$ is the curvature. If the centroid $y=y_{c}$ is taken as reference, where $\mathcal{E}\left(y_{0}\right)=0$, then:

$$
\varepsilon(y)=-\kappa\left(y-y_{c}\right)
$$

(3) the maximum tensile strain in the bottom flange is restricted by the relevant tensile strength and the crack opening criterion of the UHPC material. Specific values employed below, refer to the Ductal (sf) UHPC. Material values are given in Table 3:

(a) for the service limit state (SLS), for which zero crack opening is admissible, the maximum admissible tensile strain is

$$
\begin{aligned}
y & =y_{\min }: \varepsilon_{\mathrm{SLS}}=\frac{\Sigma_{1}^{-}}{K_{0}}=\frac{1.1}{7,820} \\
& =1.4066 \times 10^{-4},
\end{aligned}
$$

where $\Sigma_{1}^{-}$is the cracking strength of the UHPCmaterial, and $K_{0}$ the elastic stiffness of UHPC;

(b) for the ultimate limit state (ULS) of the reinforced (prestressed) structural component, for which the maximum admissible crack opening is defined by (7), the maximum admissible tensile strain for the reinforced UHPC material is

$$
\begin{aligned}
y & =y_{\min }: \varepsilon_{\mathrm{ULS}}=\frac{\Sigma_{2}}{K_{0}}+\frac{\llbracket w \rrbracket_{\mathrm{re}}^{\lim }}{(2 / 3) h} \\
& =\frac{\Sigma_{2}}{K_{0}}+\min \left(\frac{3 L_{f}}{8 h}, \frac{3}{200}\right) \\
& =\frac{1.67}{7,820}+\min \left(\frac{3(1 / 2)}{8(45)}, \frac{3}{200}\right) \\
& =4.3802 \times 10^{-3},
\end{aligned}
$$

Table 3: Material identity card for Ductal (sf). Mean values obtained from direct notched tensile plate tests.

\begin{tabular}{lcc}
\hline & Symbol & Mean value ksi (MPa) \\
\hline Compressive strength & $f_{c}^{\prime}$ & $28(193)$ \\
Initial stiffness & $K_{0}$ & $7,820(53,917)$ \\
Postcracking stiffness & $K_{1}$ & $233(1,606)$ \\
Cracking strength & $\Sigma_{1}^{-}$ & $1.1(7.6)$ \\
Postcracking strength & $\Sigma_{1}^{+}$ & $1.0(6.9)$ \\
Ductile strength & $\Sigma_{2}$ & $1.67(11.5)$ \\
Fiber length & $L_{f}$ & 0.5 in $(1.27 \mathrm{~cm})$ \\
\hline
\end{tabular}

where $\Sigma_{2}$ is the ductile yield strength of the UHPC material, $L_{f}$ the fiber length in the UHPC, and $h$ the UHPC-beam depth;

(4) the stress strain behavior of UHPC is described by the following relations:

(a) UHPC compressive behavior:

$$
0 \geq \sigma=K_{0} \varepsilon \geq-f_{c}^{\prime},
$$

where $f_{c}^{\prime}$ is the UHPC compressive strength;

(b) UHPC elastic tensile behavior:

$$
0 \leq \varepsilon \leq \varepsilon_{\text {SLS }}: \sigma=K_{0} \varepsilon
$$

(c) UHPC postcracking behavior:

$$
\varepsilon_{\mathrm{SLS}}<\varepsilon \leq \mathcal{E}_{\mathrm{ULS}}: \sigma=\Sigma_{1}^{+}+K_{1}\left(\varepsilon-\varepsilon_{\mathrm{SLS}}\right) \leq \Sigma_{2},
$$

where $\Sigma_{1}^{+}$is the postcracking strength, and $K_{1}$ is the postcracking stiffness. Figure 4(b) displays the tension stress strain curve for a UHPC material. The material values required to carry out the calculation are two stiffness constants $K_{0} ; K_{1}$ and four strength values: the compressive strength $f_{c}^{\prime}$, the cracking strength $\Sigma_{1}^{-}$, the postcracking strength $\Sigma_{1}^{+}$, and the ductile yield limit. These values are determined from a tensile notched plate test and constitute the "material identity card" of a specific UHPC material. Table 3 reports the values for Ductal (sf) of Lafarge. It is important to note that the values to be used in the determination of the mean strength capacity are mean values, and not characteristic values.

The relations presented in this section define a wellposed problem for the determination of the maximum mean moment capacity of a section. The solution is iterative and is conveniently achieved using a spreadsheet calculation. The input to these calculations are (1) the material values for UHPC ("material identity card"), and (slab) concrete $\left(E_{\mathrm{cs}}=2,917 \mathrm{ksi}(20.1 \mathrm{GPa}), f_{\mathrm{cs}}^{\prime}=4.0 \mathrm{ksi}(28 \mathrm{MPa})\right)$ and prestressing strands $\left(E_{T}=29,000 \mathrm{ksi}(200 \mathrm{GPa}), f_{y}^{p}=270 \mathrm{ksi}\right.$ 


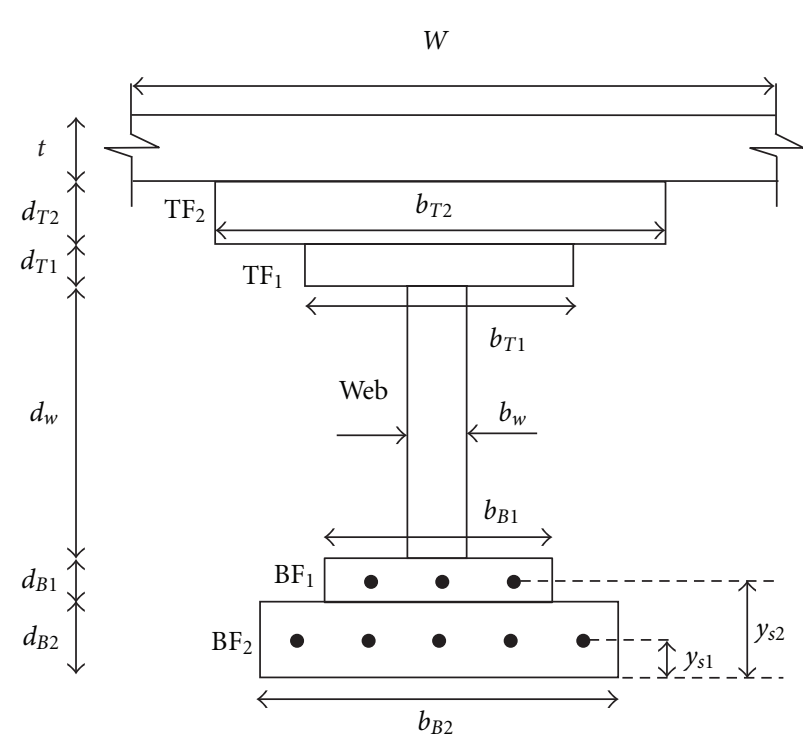

(a)

\begin{tabular}{|l|c|c|}
\hline & Symbol & $\begin{array}{c}\text { Dimension } \\
\text { mm (in) }\end{array}$ \\
\hline Slab & $W$ & $1143(45)$ \\
\hline UHPC-beam & $t$ & $203(8)$ \\
\hline $\mathrm{TF}_{2}$ & $b_{T 2}$ & $1194(47)$ \\
\hline & $d_{T 2}$ & $102(4)$ \\
\hline $\mathrm{TF}_{1}$ & $b_{T 1}$ & $686(27)$ \\
\hline & $d_{T 1}$ & $38(1.5)$ \\
\hline $\mathrm{Web}$ & $b_{w}$ & $178(7)$ \\
\hline & $d_{w}$ & $737(29)$ \\
\hline $\mathrm{BF}_{1}$ & $d_{B 1}$ & $584(23)$ \\
\hline & $b_{B 1}$ & $89(3.5)$ \\
\hline $\mathrm{BF}_{2}$ & $b_{B 2}$ & $813(32)$ \\
\hline & $d_{B 2}$ & $178(7)$ \\
\hline
\end{tabular}

(b)

FIGURE 5: Idealization of the UHPC PCBT-45 VDOT section with slab.

$(1,862 \mathrm{MPa})),(2)$ the section dimensions, including the concrete slab, and (3) the section and position of the prestressing strands, and the prestress level. For these input data, solving the set of equations described above yields the mean moment capacity of the section for SLS and ULS, that is, formally:

$$
M_{R}^{J}=F \text { (Materials, Section, Prestressing); } \quad J=\text { SLS, ULS. }
$$

6.1.2. Design Moment Capacity. The design moment capacity of the section is the factored mean moment capacity $\phi_{M} \times$ $M_{R}^{J}$, where $\phi$ is the design factor, which reduces the mean moment capacity of the UHPC section to its characteristic value:

$$
\phi_{M} M_{R}^{J}=M_{R}^{J}-1.75 \times s_{M}^{J}=\left(1-1.75 \times \frac{s_{M}^{J}}{M_{R}^{J}}\right) M_{R}^{J},
$$

where $M_{R}^{J}$ is the mean moment capacity value, and $s_{M}$ the standard deviation of the moment capacity of the section under consideration. In the absence of such data, the design factor for bending can be determined for a specific UHPC material from a series of flexural tests on small-sized specimen, yielding mean value $M_{R}^{J}$ and standard deviation $s_{M}^{J}$ for the flexural strength of the model UHPC structure, from which:

$$
\phi_{M}=1-1.75 \times \frac{s_{M}^{J}}{M_{R}^{J}} .
$$

Such an investigation was carried out for Ductal, which showed for both SLS and ULS:

$$
\text { Bending }: \phi_{M}=0.85 \text {. }
$$

Similar tests have been carried out for other UHPC materials, which confirmed that the value of $\phi_{M}=0.85$ in bending is a safe estimate to account for the behavior of UHPC materials in flexural structures. The factor of $\phi_{M}=0.85$ can also (and should) be used for onsite quality control purposes. It suffices to carry out a sufficient number of flexural tensile strength tests on small control prisms, made of the same UHPC material as the one used in the structure, and determine the mean value and the standard deviation. The factor $\phi_{M}$ determined from the flexural tensile-strength checks, then, should be greater or equal to $\phi_{M}=0.85$.

6.1.3. Determination of Prestressing Strands for PCBT-45 VDOT Bulb-T Section. As most of the design parameters, including the material properties, were fixed in the provided design problem, the design focus was on the prestressing force per beam. To this end, the PCBT-45 VDOT Bulb-T section with concrete slab is discretized into elements of constant width shown in Figure 5, which also shows the parameters used in the design. The effective slab width contributing to the composition section is estimated from:

$$
\begin{aligned}
W & =\frac{1}{n} \min \left(\frac{L}{4}, 12 t+\max \left(b_{w}, \frac{b_{T 2}}{2}\right), S\right) \\
& =\frac{1}{2.68} \min \left(\frac{108(12)}{4}, 12(8)+\max \left(7, \frac{47}{2}\right), 10.08(12)\right) \\
& =45 \mathrm{in}=1.143 \mathrm{~m} .
\end{aligned}
$$

The aim of the analysis is to determine the required prestressing force (or number of prestressing strands), which satisfies the design criteria (2) and (4):

$$
\begin{aligned}
& M_{\mathrm{SLS}}\left(x_{M}\right) \leq 0.85 \times M_{R}^{\mathrm{SLS}}\left(\gamma, A_{s 1}, A_{s 2}, y_{s 1}, y_{s 2}\right), \\
& M_{\mathrm{ULS}}\left(x_{M}\right) \leq 0.85 \times M_{R}^{\mathrm{ULS}}\left(\gamma, A_{s 1}, A_{s 2}, y_{s 1}, y_{s 2}\right),
\end{aligned}
$$




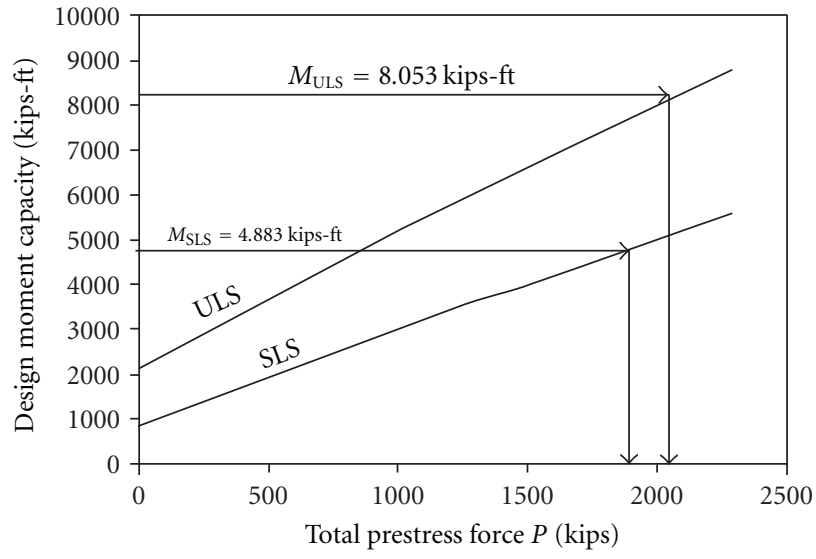

(a)

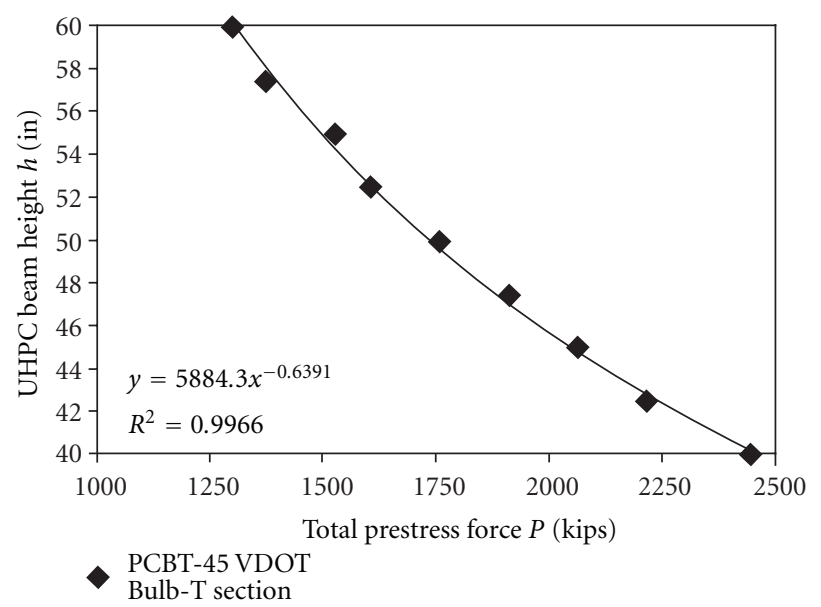

(b)

FIGURE 6: (a) Design moment capacity of the composite section as a function of the total prestressing force; (b) UHPC beam height versus required prestressing force satisfying SLS and ULS factored design moments.

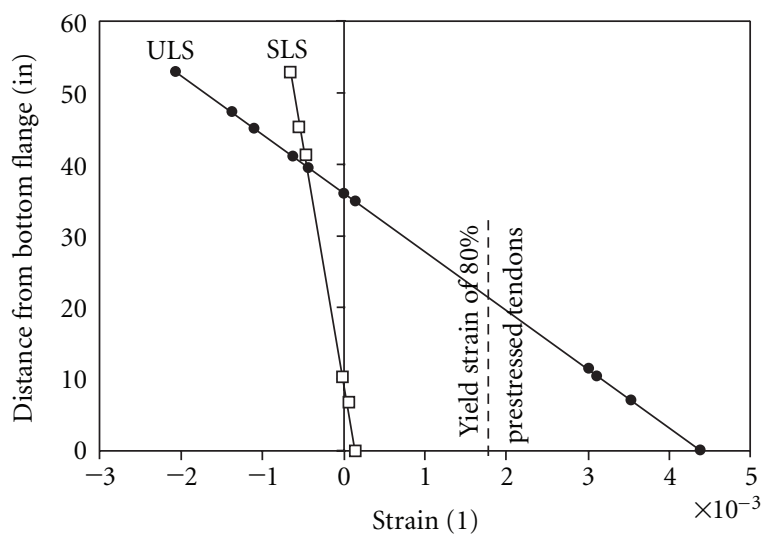

(a)

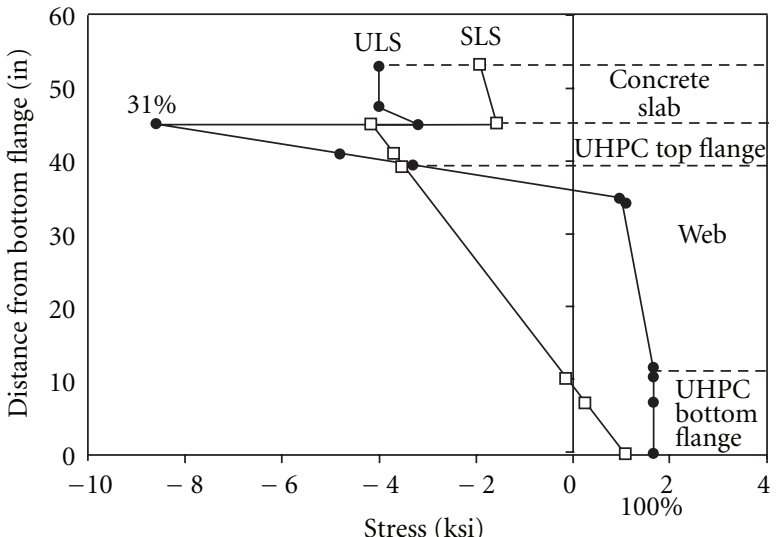

(b)

FIgURE 7: Strain (a) and stress (b) profiles in the beam section at SLS and ULS.

where $M_{\mathrm{SLS}}\left(x_{M}\right)=4,883 \mathrm{kips}-\mathrm{ft}(6,620 \mathrm{kN}-\mathrm{m})$ and $M_{\mathrm{ULS}}$ $\left(x_{M}\right)=8,053$ kips-ft $(10,918 \mathrm{kN}-\mathrm{m})$ are the design moments (8) and (10), $\gamma$ is the prestressing level, $A_{s 1}$ and $A_{s 2}$ are the strand section positioned at $y_{s 1}$ and $y_{s 1}$, respectively, (see Figure 5).

We will assume the prestressing level to be $\gamma=0.8$ (after loss of prestressing due to creep, etc.) and optimize the number of prestressing strands until (26) are met simultaneously. Figure 6(a) displays the design moment capacity as a function of the total prestress force for both the SLS and the ULS. Subjected to bending, the governing limit state is generally the ultimate limit state. The required total prestressing force per beam is approximately calculated as:

$$
P=f_{y}^{p}\left(A_{s 1}+A_{s 2}\right) \approx 2,100 \text { kips }=9,341 \mathrm{kN} .
$$

It can be achieved with either $40 \times 0.5$ in $(1.27 \mathrm{~cm})$ diameter strands (in three layers 2 in $(5 \mathrm{~cm})$ spacing, 15-15-10) or $27 \times$ 0.6 in $(1.524 \mathrm{~cm})$ diameter strands (in two layers 2 in $(5 \mathrm{~cm})$ spacing 15-12). Figure 7 displays the strain and stress profiles over the cross-section. The section in the ULS is cracked to a height of roughly 35 in $(88.9 \mathrm{~cm})$ from the bottom flange. However, what is important to note in Figure 7 is that the compressive stress in the UHPC top flange in the ultimate limit state is only at $31 \%$ of its compressive strength capacity, while the concrete compressive slab is already at yield. On the other hand, the tension side is at the UHPC tensile yield capacity (by design), and the prestressing tendons are also at yield.

\subsection{Shear Capacity of Section}

6.2.1. Service Limit State. In the service limit state, the maximum tensile stress generated by the two nonzero stress components $(\sigma, \tau)$ must be smaller than the cracking strength $\Sigma_{1}^{-}$:

$$
\sigma_{1}=\frac{\sigma}{2}+\sqrt{\left(\frac{\sigma}{2}\right)^{2}+\tau^{2}} \leq \Sigma_{1}^{-}
$$


The maximum admissible shear stress, therefore, is

$$
\tau_{\lim }=\Sigma_{1}^{-} \sqrt{1-\frac{\sigma}{\Sigma_{1}^{-}}} .
$$

The SLS shear strength capacity is given by

$$
V_{R}^{\mathrm{SLS}}=A_{w}^{\mathrm{eff}} \Sigma_{1}^{-} \sqrt{1-\frac{\sigma}{\Sigma_{1}^{-}}}
$$

where $A_{w}^{\text {eff }}$ is the effective shear section, that can be estimated as $A_{w}^{\text {eff }} \approx b_{w} d_{w}=203 \mathrm{in}^{2}\left(1,310 \mathrm{~cm}^{2}\right)$, and the longitudinal stress (close to the support) from the prestressing force $\sigma \approx$ $-0.8 \times 2100 / 1096=-1.5 \mathrm{ksi}(10.34 \mathrm{MPa})$. Whence,

$$
V_{R}^{\text {SLS }}=203(1.1) \sqrt{1-\frac{(-1.5)}{1.1}}=343 \mathrm{kips}=1,526 \mathrm{kN} .
$$

The mean design load need to be reduced to its characteristic value by means of the shear design factor $\phi_{V}=0.85$. Then using (9) and (31) in (2), the SLS-shear design check reads:

$$
\begin{aligned}
V_{\mathrm{SLS}}\left(x_{V}\right) & =195[\mathrm{kips}]<\phi V_{R}^{\mathrm{SLS}}=0.85 \times 343 \\
& =292 \mathrm{kips}=1,299 \mathrm{kN} .
\end{aligned}
$$

6.2.2. Ultimate Limit State. The ULS-shear design check is based on the premise that crack-bridging fibers, after cracking of the UHPC, carry a part of the shear load; very similar to shear reinforcement. In the absence of shear reinforcement, the ULS shear capacity of the section is determined by

$$
\phi_{V} V_{R}^{\mathrm{ULS}}=\phi_{c} V_{c}+\phi_{f} V_{f}
$$

where $V_{c}$ is the contribution of the UHPC concrete, according to AFGC recommendations [18]:

$$
V_{c}=0.09 \sqrt{f_{c}^{\prime}} b_{w} z=0.09 \sqrt{28}(7)(41.5)=138 \mathrm{kips}=614 \mathrm{kN} \text {, }
$$

with $b_{w}$ : web thickness and $z$ : the effective height-within the UHPC section-between the prestressing cable and the compression flange, here $z \approx 45-3.5=41.5$ in $(105.4 \mathrm{~cm})$. In (33), $V_{f}$ is the contribution of the fibers:

$$
V_{f}=\frac{A \sigma_{p}}{\tan \beta_{u}}
$$

where $A$ is the area of fiber effect, estimated for bulb-T sections with $A=b_{w} z ; \beta_{u}$ is the inclination angle of the compression struts, lower-bounded by $\beta_{u}=30^{\circ}$, and $\sigma_{p}$ is the residual UHPC tensile strength defined by

$$
\sigma_{p}=\frac{1}{\llbracket w \rrbracket^{\lim }} \int_{0}^{\llbracket w \rrbracket^{\lim }} \sigma(s) d s
$$

In this expression, $\llbracket w \rrbracket^{\lim }$ is the admissible crack opening defined by (6) for unreinforced elements and by (7) for reinforced elements, and $\sigma=\sigma(\llbracket w \rrbracket)$ is the stress after crack opening. For the stress strain behavior displayed in Figure 3, relation (36) can be expressed in terms of the strain:

$$
\sigma_{p}=\frac{1}{\mathcal{E}_{\mathrm{ULS}}-\varepsilon_{\mathrm{SLS}}} \int_{\varepsilon_{\mathrm{SLS}}}^{\varepsilon_{\mathrm{ULS}}} \sigma(s) d s
$$

where $\varepsilon_{U L S}$ corresponds to the strain when the maximum crack opening is reached; analogous to (17), but written here for a structural element (the web) unreinforced with regard to shear, it reads:

$$
\varepsilon_{\mathrm{ULS}}=\frac{\Sigma_{2}}{K_{0}}+\frac{3}{2} \frac{\llbracket w \rrbracket_{\mathrm{un}}^{\lim }}{h}=\frac{1.67}{7,820}+\frac{0.01}{45}=4.3578 \times 10^{-4} .
$$

In (37), $\varepsilon_{\text {SLS }}=\Sigma_{1}^{-} / K_{0}$ corresponds to the strain at the onset of cracking:

$$
\varepsilon_{\text {SLS }}=\frac{1.1}{7,820}=1.4066 \times 10^{-4} .
$$

In order to evaluate the integral in (37), we need to check whether the ductile yield strength is reached at $\varepsilon_{\mathrm{ULS}}$, by calculating the strain corresponding to the onset of yielding:

$$
\begin{aligned}
\mathcal{E}_{2} & =\varepsilon_{\text {SLS }}+\frac{\Sigma_{2}-\Sigma_{1}^{+}}{K_{1}} \\
& =1.4066 \times 10^{-4}+\frac{1.67-1.0}{233}=3.0162 \times 10^{-3} .
\end{aligned}
$$

Since $\varepsilon_{2}>\varepsilon_{\mathrm{ULS}}$, the yield strength is not reached, and the integral in (37) is evaluated from:

$$
\begin{aligned}
\int_{\varepsilon_{S L S}}^{\varepsilon_{\mathrm{ULS}}} \sigma(s) d s= & \Sigma_{1}^{+}\left(\varepsilon_{\mathrm{ULS}}-\varepsilon_{\mathrm{SLS}}\right)+\frac{K_{1}}{2}\left(\varepsilon_{\mathrm{ULS}}-\varepsilon_{\mathrm{SLS}}\right)^{2} \\
= & 1.0(4.3578-1.4066) \times 10^{-3} \\
& +\frac{233}{2}(4.3578-1.4066)^{2} \times 10^{-3} \\
= & 3.9659 \times 10^{-3} \mathrm{ksi}=27.34 \times 10^{-3} \mathrm{MPa}
\end{aligned}
$$

Finally,

$$
\sigma_{p}=\frac{3.9659 \times 10^{-3}}{(4.3578-1.4066) \times 10^{-3}}=1.34 \mathrm{ksi}=9.24 \mathrm{MPa} .
$$

The fiber contribution to the shear force thus reads:

$$
V_{f}=\frac{7(41.5)(1.34)}{\tan 30}=675 \mathrm{kips}=3,003 \mathrm{kN} .
$$

The characteristic shear capacity is obtained from (33) using (34) and (43), together with the design factors $\phi_{c}=2 / 3$ and $\phi_{f}=0.8 \times 0.85 \approx 2 / 3$ (the design factor for the fiber participation accounts for two phenomena: fibers are eventually not ideally randomly oriented, which is captured by the first factor $1 / 1.25=0.8$, in addition to the intrinsic variability of the material properties of the UHPC that is taken into account by the second factor $\left.\phi_{V}=0.85\right)$ :

$$
\phi_{V} V_{R}^{\mathrm{ULS}}=\frac{2}{3}(138+675)=542 \mathrm{kips}=2,411 \mathrm{kN} .
$$


The ULS-shear design check reads:

$$
V_{\mathrm{ULS}}\left(x_{V}\right)=333[\mathrm{kips}]<\phi_{V} V_{R}^{\mathrm{ULS}}=542 \mathrm{kips}=2,411 \mathrm{kN} \text {. }
$$

\section{Discussion of Results}

(1) an immediate observation from the results of the preliminary design implementation is that for the beam spacing $(S \approx 10 \mathrm{ft}(3.05 \mathrm{~m}))$ specified in this problem, the longest span that can be crossed by a typical VDOT PCBT-45 section made of concrete with a compressive strength up to $8 \mathrm{ksi}(55.2 \mathrm{MPa})$ is given as $90 \mathrm{ft}(27.4 \mathrm{~m})$ in the related VDOT manual [21]. In this particular design, not only is the section sufficient for a $108 \mathrm{ft}(32.92 \mathrm{~m})$ span, but also the compressive stress at the UHPC top flange is less than $1 / 3$ its strength, which suggests that a longer span can be crossed using the same beam section. Alternatively, a smaller UHPC section could be sufficient for the same span;

(2) as a result of span length, the preliminary design of the composite section shows that a relatively high prestressing force is required of roughly 2,100 kips $(9,341 \mathrm{kN})$. The high compressive strength capacity of UHPC does allow such a high level of prestressing. In return, the prestressing transfer must be carefully analyzed and designed. While shear reinforcement is clearly not required, it may eventually be necessary to reinforce the anchorage zone to limit the risk of transversal tensile stresses and to ensure a smooth stress transfer from the bottom flange into the beam;

(3) an increase of the web height would obviously reduce the required prestressing force. However, we should note that an increase of the UHPC beam height would reduce the admissible limit strain $\varepsilon_{U L S}$ according to (17) in the ULS-bending design. As a consequence, for a given design moment, the required prestressing force does not scale according to $P \propto$ $h^{-1}$, but according to $P \propto h^{-\alpha}$, where $\alpha>1$. As an example, Figure 6(b) plots the height as a function of the required prestressing force that satisfies the SLS and ULS design moments (26) and (28). The fitted power function in this figure shows that $\alpha=$ $1 / 0.6391=1.5647>1$;

(4) there are many optimization possibilities: the web width can be reduced to 6 inch $(15.2 \mathrm{~cm})$ without affecting the conclusions of the preliminary bending and shear design presented here. The conclusions are also not affected by a change in the prestress level within $0.75<\gamma<1.0$ in SLS and ULS. The UHPC top flange which is overdesigned (elastic in the ULS), could eventually be eliminated, if not required for other purposes. Further optimization would aim at reducing the relatively high moment due to deadweight. The most efficient optimization consists in replacing the concrete slab by an integrated UHPC slab. Such an optimization would allow reduction of the beam height, which in turn would lead to higher admissible limit strains $\mathcal{E}_{\mathrm{ULS}}$ in (17);

(5) a detailed design calculation of the prestressing of the beams and prestress losses, anchorage zone, and so forth, needs to follow.

\section{Current Status and Future Prospects of UHPC in Bridge Structures}

The authors of this paper are yet to come across a publication on UHPC that does not recognize its great potential for enabling construction of lighter, stronger, more durable, better looking, and more environmentally friendly concrete structures. However, relatively high cost of the material, unfamiliarity of the industry with the material, more involved production and handling processes, and the lack of related codes and specifications are the barriers against its common use in bridge structures $[14,15,22]$. So far, implementation of UHPC in bridge structures has generally been in the form of pilot projects in which the design did not significantly deviate from conventional geometry and dimensions to take full advantage of the favorable behavior and strength properties of the material. Initial research and applications revealed the need for optimized structural shapes that better makes use of the mechanical and durability properties of UHPC. The pi girder developed as a result of the FHWA initiated research program is an important achievement to this effect.

The primary needs associated with UHPC can be grouped as: (1) characterization of material properties; (2) development of analysis and design methods; (3) development of related codes and specifications; (4) development of optimized member designs that make better use of the material. As familiarity with UHPC increases, wider use the material in bridge projects is anticipated. Reduced material costs as a result of the increase in demand combined with development of better structural shapes and associated design methods will fuel common use of UHPC materials to build strong and durable bridge structures.

Combination of UHPC with other advanced composite materials such as the fiber reinforced polymers (FRP) is another exciting area of research with high impact potential [23]. Use of FRPs in conjunction with UHPC may make a positive contribution to the durability of the structure and may introduce further design optimization opportunities that may allow more efficient use of materials.

\section{Conclusion}

Implementation of a UHPC material model in a preliminary design problem is performed in this paper. Such mechanistic models that can accurately capture the behavior of the UHPC material can be used for model based optimization of design to develop more efficient member geometries. Knowledge of the UHPC material properties and the initial results obtained from design implementations reinforce the authors' belief that UHPC has much to offer in the future to address not only the strength and durability challenges but also those 
associated with the economy and environmental impact of concrete bridges.

\section{Acknowledgments}

Part of this research performed at MIT was supported by the Lafarge Group, whose financial support is gratefully acknowledged. The preliminary design case study was provided by Virginia Department of Transportation. The authors thank Halil Ibrahim Andic, a graduate student at METU, for his assistance with the illustrations in the paper.

\section{References}

[1] FHWA, "National Bridge Inventory Data," US Department of Transportation, Federal Highway Administration, 2010, http://www.fhwa.dot.gov/bridge/britab.cfm.

[2] FHWA, Our Nation's Highways, US Department of Transportation, Federal Highway Administration, Washington, DC, USA, 2010.

[3] ASCE, Report Card for America's Infrastructures, American Society of Civil Engineers, Reston, VA, USA, 2009.

[4] H. Park, F.-J. Ulm, and E. Chuang, Model-Based Optimization of Ultra High Performance Concrete Highway Bridge Girders. CEE Report R03 -01, Massachusetts Institute of Technology, Boston, Mass, USA, 2003.

[5] F. de Larrard and T. Sedran, "Optimization of ultra-high-performance concrete by the use of a packing model," Cement and Concrete Research, vol. 24, no. 6, pp. 997-1009, 1994.

[6] P. Rossi, "High performance multimodal fiber reinforced cement composites (HPMFRCC): The LCPC experience," ACI Materials Journal, vol. 94, no. 6, pp. 478-483, 1997.

[7] P. Acker and M. Behloul, "Ductal Technology: A Large Spectrum of Properties, A Wide Range of Applications," in Proceedings of the International Symposium on Ultra High Performance Concrete, M. Schmidt, E. Fehling, and C. Geisenhanslüke, Eds., Kassel, Germany, September 2004.

[8] A. Simon, Z. Hajar, D. Lecointre, and J. Petitjean, "Realization of two road bridges with ultra-high-performance fibre-reinforced concrete," in Proceedings of the 6th International Symposium on High Strength/ High Performance Concrete, 2002.

[9] G. Brouwer, "Bridge to the future," Civil Engineering Magazine, vol. 71, no. 11, 2001.

[10] "Canadian Precast/Prestressed Concrete Institute," http:// www.cpci.ca.

[11] B. A. Graybeal, Ultra-High Performance Concrete, FHWAHRT-11-038, Federal Highway Administration, Washington, DC, USA, 2011.

[12] B. A. Graybeal, Material Property Characterization of UltraHigh Performance Concrete, FHWA-HRT-06-103, Federal Highway Administration, Washington, DC, USA, 2006.

[13] B. A. Graybeal, Structural Behavior of Ultra-High Performance Concrete Prestressed I Girders, FHWA-HRT-06-115, Federal Highway Administration, Washington, DC, USA, 2006.

[14] B. A. Graybeal and M. M. Lwin, "Deployment of Ultra-HighPerformance Concrete Technology," ASPIRE, Summer 2010.

[15] C. Ozyildirim, "Evaluation of Ultra-High-Performance FiberReinforced Concrete, Final Report VCTIR 12-R1," Virginia Center for Transportation Innovation and Research, Charlottesville, VA, USA, 2011, http://www.virginiadot.org/vtrc/ main/online_reports/pdf/12-r1.pdf.
[16] T. Wipf, S. Sritharan, A. Abu-Hawash, B. Phares, and D. Bierwagen, Iowa's Ultra-High Performance Concrete Implementation, Iowa Department of Transportation, Ames, Iowa, USA, 2011.

[17] V. C. Li, "From micromechanics to structural engineeringthe design of cementitious composites for civil engineering applications," Journal of Structural Engineering and Earthquake Engineering, vol. 44, no. 10, pp. 1565-1586, 1993.

[18] AFGC, "Service d'études techniques des routes et autoroutes Association Française de Génie Civil (SETRA-AFGC). Bétons fibreés à ultra-hautes performances -Recommandations provisoires (Ultra High Performance Fibre Reinforced ConcretesInterim Roccomendations)," Bagneux, France, 2002.

[19] E. Y. Chuang and F. J. Ulm, "Two-phase composite model for high performance cementitious composites," Journal of Engineering Mechanics, vol. 128, no. 12, pp. 1314-1323, 2002.

[20] AASHTO, AASHTO LRFD Bridge Design Specifications, American Association of State Highway and Transportation Officials, Washington, DC, USA, 2002.

[21] VDOT, Manual of the Structure and Bridge Division, Volume V-Part 2, Design Aids - Typical Details, Virginia Department of Transportation, Richmond, VA, USA, 2011.

[22] T. M. Ahlborn, E. J. Peuse, and D. L. Misson, Ultra-HighPerformance-Concrete for Michigan Bridges Material Performance-Phase I, Michigan Department of Transportation, MDOT RC-1525, CSD-2008-11, Lansing, MI, USA, 2008.

[23] D. Chen and R. El-Hacha, "Behaviour of hybrid FRP-UHPC beams in flexure under fatigue loading," Composite Structures, vol. 94, pp. 253-266, 2011. 

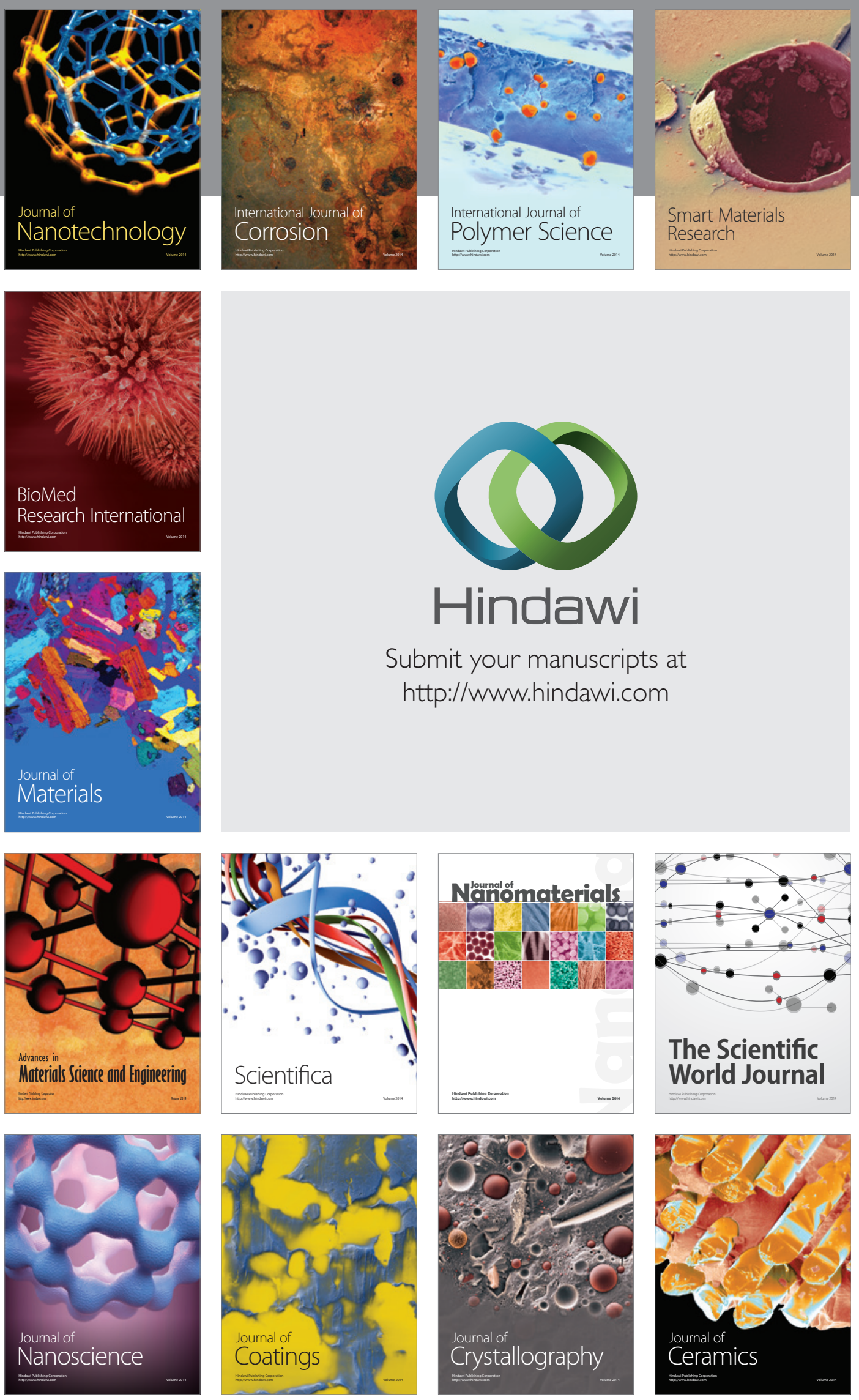

The Scientific World Journal

Submit your manuscripts at

http://www.hindawi.com

\section{World Journal}

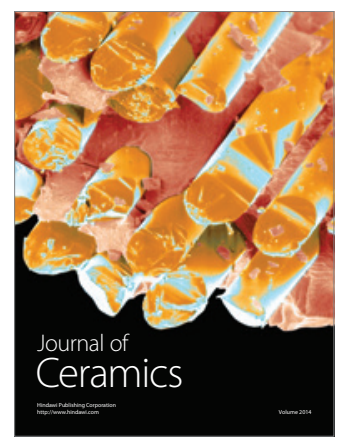

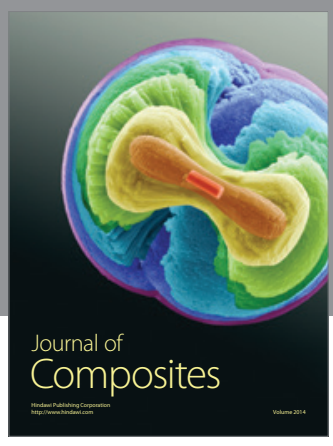
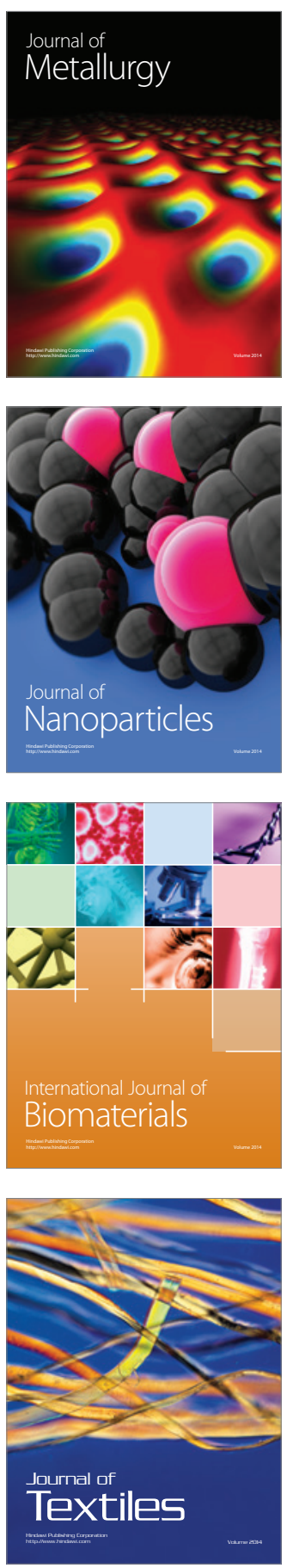